This is an electronic reprint of the original article. This reprint may differ from the original in pagination and typographic detail.

\author{
Author(s): Gaelings, Lana; Söderholm, Sandra; Bugai, Andrii; Fu, Yu; Nandania, Jatin; Schepens, \\ Bert; Lorey, Martina B.; Tynell, Janne; Ginste, Liesbeth Vande; Goffic, Ronan Le; Miller, \\ Matthew S.; Kuisma, Marika; Marjomäki, Varpu; De Brabander, Jef; Matikainen, \\ Sampsa; Nyman, Tuula A.; Bamford, Dennis; Saelens, Xavier; Julkunen, Ilkka; \\ Paavilainen, Henrik; Hukkanen, Veijo; Velagapudi, Vidya; Kainov, Denis E.
}

Title: Regulation of Kynurenine Biosynthesis during Influenza Virus Infection

Year: $\quad 2017$

Version:

Please cite the original version:

Gaelings, L., Söderholm, S., Bugai, A., Fu, Y., Nandania, J., Schepens, B., Lorey, M. B., Tynell, J., Ginste, L. V., Goffic, R. L., Miller, M. S., Kuisma, M., Marjomäki, V., De Brabander, J., Matikainen, S., Nyman, T. A., Bamford, D., Saelens, X., Julkunen, I., . . . Kainov, D. E. (2017). Regulation of Kynurenine Biosynthesis during Influenza Virus Infection. FEBS Journal, 284(2), 222-236. https://doi.org/10.1111/febs.13966

All material supplied via JYX is protected by copyright and other intellectual property rights, and duplication or sale of all or part of any of the repository collections is not permitted, except that material may be duplicated by you for your research use or educational purposes in electronic or print form. You must obtain permission for any other use. Electronic or print copies may not be offered, whether for sale or otherwise to anyone who is not an authorised user. 


\section{Regulation of Kynurenine Biosynthesis during Influenza Virus Infection}

Lana Gaelings ${ }^{1 \#}$, Sandra Söderholm ${ }^{2,3 \#}$, Andrii Bugai ${ }^{4 \#}, \mathrm{Yu} \mathrm{Fu}^{1}$, Jatin Nandania ${ }^{1}$, Bert Schepens ${ }^{5,6}$, Martina B. Lorey ${ }^{3}$, Janne Tynell ${ }^{7}$, Liesbeth Vande Ginste ${ }^{4,5}$, Ronan Le Goffic ${ }^{8}$, Matthew S. Miller ${ }^{9}$, Marika Kuisma ${ }^{4}$, Varpu Marjomäki ${ }^{10}$, Jef De Brabander ${ }^{11}$, Sampsa Matikainen ${ }^{3}$, Tuula A. Nyman ${ }^{12}$, Dennis Bamford ${ }^{2}$, Xavier Saelens ${ }^{4,5}$, Ilkka Julkunen ${ }^{7,13}$, Henrik Paavilainen ${ }^{13}$, Veijo Hukkanen ${ }^{13}$, Vidya Velagapudi $^{1}$ and Denis E. Kainov ${ }^{1}$

${ }^{1}$ From the Institute for Molecular Medicine Finland (FIMM), University of Helsinki, Finland;

${ }^{2}$ From the Institute of Biotechnology (BI), University of Helsinki, Finland;

${ }^{3}$ From the Finnish Institute of Occupational Health (TTL), Helsinki, Finland;

${ }^{4}$ From the Medicum, Department of Biochemistry and Developmental Biology, University of Helsinki, Finland;

${ }^{5}$ From the Medical Biotechnology Center, VIB, Ghent, Belgium;

${ }^{6}$ From the department of Biomedical Molecular Biology, Ghent University, Ghent, Belgium.

${ }^{7}$ From the National Institute for Health and Welfare (THL), Helsinki, 00271, Finland;

${ }^{8}$ From the Centre de Recherche de Jouy-en-Josas UR0892 Unité VIM - Virologie \& Immunologie

Moléculaires, Domaine de Vilvert, Jouy-en-Josas, France;

${ }^{9}$ From the Department of Biochemistry and Biomedical Sciences, Institute for Infectious Diseases

Research, McMaster Immunology Research Centre, McMaster University, Hamilton, Ontario,

Canada.

${ }^{10}$ From the Department of Biological and Environmental Science, Nanoscience Center, University of Jyväskylä, Jyväskylä, Finland;

${ }^{11}$ From the department of Biochemistry, University of Texas Southwestern Medical Center, Dallas, USA;

${ }^{12}$ From the Institute of Clinical Medicine, Sognsvannsveien 20, Rikshospitalet, 0372 Oslo, Norway

${ }^{13}$ From the department of Virology, University of Turku, Turku, 20014, Finland.

${ }^{\#}$ These authors contributed equally.

Correspondence: Vidya Velagapudi and Denis E. Kainov, Institute for Molecular Medicine Finland, Tukholmankatu 8, 00290, Helsinki, Finland. Tel: +358504155460; Fax: +3581912 5737; Email: denis.kainov@helsinki.fi or vidya.velagapudi@helsinki.fi

Running title: Reprogramming kynurenine biosynthesis during influenza virus infection

Article type: Original Article

Keywords: indoleamine-pyrrole 2,3-dioxygenase (IDO1); influenza virus; innate immunity; hostpathogen interaction; interferon.

Conflict of interest: The authors declare that they have no conflicts of interest with the contents of this article.

Abbreviations: IAV, influenza A viruses; EV1, echovirus 1; HSV, herpes simplex virus; IDO1, indoleamine-pyrrole 2,3-dioxygenase; TDO2, Tryptophan 2,3-dioxygenase; KP, kynurenine pathway; dsRNA, double-stranded RNA; IFN, interferon; NS1, nonstructural protein 1; 3-HAA, 3hydroxyanthranilic acid; 5-HT, 5-hydroxytryptophan; NAD, nicotinamide adenine dinucleotide; 5HIAA, 5-hydroxyindole-3-acetic acid; 3-HK, 3-hydroxykynurenine; LC-MS, liquid chromatography with mass spectrometry; Trp, tryptophan; LPS, lipopolysaccharides; SaliPhe, saliphenylhalamide; FC, This article has been accepted for publication and undergone full peer review but has not been through the copyediting, typesetting, pagination and proofreading process, which may lead to differences between this version and the Version of Record. Please cite this article as doi: 10.1111/febs.13966

This article is protected by copyright. All rights reserved. 
fold change; PRR, pattern recognition receptor; RBD, RNA-binding domain; ED, effector domain; moi, multiplicity of infection; PFU, particle forming unit; hpi, hours post infection.

\begin{abstract}
Influenza A viruses (IAVs) remain serious threats to public health because of the shortage of effective means of control. Developing more effective virus control modalities requires better understanding of virus-host interactions. It has previously been shown that IAV induces the production of kynurenine, which suppresses T-cell responses, enhances pain hypersensitivity and disturbs behaviour in infected animals. However, the regulation of kynurenine biosynthesis during IAV infection remains elusive. Here we showed that IAV infection induced expression of interferons (IFNs), which upregulated production of indoleamine-2,3-dioxygenase (IDO1), which catalysed the kynurenine biosynthesis. Furthermore, IAV attenuated the IDOI expression and the production of kynurenine through its NS1 protein. Interestingly, inhibition of viral replication prior to IFN induction limited IDOI expression, while inhibition after did not. Finally, we showed that kynurenine biosynthesis was activated in macrophages in response to other stimuli, such as influenza B virus, herpes simplex virus 1 and 2 as well as bacterial lipopolysaccharides. Thus, the tight regulation of the kynurenine biosynthesis by host cell and, perhaps, pathogen might be a basic signature of a wide range of host-pathogen interactions, which should be taken into account during development of novel antiviral and antibacterial drugs.
\end{abstract}

\title{
Introduction
}

Influenza A viruses are important human pathogens that cause global epidemics and pandemics (www.who.int). It is estimated that IAVs are responsible for up to half a million deaths a year [1]. The successful recovery from viral infection largely depends on an efficient activation of innate and adaptive immune responses [2]. Metabolic responses are a part of this mechanism [3]. In particular, infected organisms reprogram their amino acid, lipid, and sugar metabolism in order to produce immune- and neuro-mediators, as well as to lower levels of energy and viral building blocks [4-13].

Alteration of the kynurenine pathway (KP) of tryptophan metabolism is one of the metabolic responses to IAV infection [14]. The major enzymes and substrates of the KP are shown in Figure 1. The enzymatic reactions proceed from tryptophan through a number of steps, with some of the key metabolic intermediates which are kynurenine, 3-hydroxyanthranilate and quinolinate [15]. These compounds can modulate the activity of the immune and central nervous systems. The first enzymes of the KP are IDO1 and tryptophan 2,3-dioxygenase (TDO2) [16]. TDO2 is mainly expressed in hepatocytes, whereas IDO1 is found in most cell types, including macrophages. The expression of IDO1 was shown to be upregulated in response to IAV infection through interferon (IFN) pathway $[12,17,18]$. Moreover, the overexpression of IDO1 was associated with cytokine overproduction, suppression of T-cell response, pain hypersensitivity and behavioural disturbances [11, 19-23]. The neurological symptoms were linked to high levels of kynurenine, the product of IDO1 catalysis. This strongly indicates that IDO1 and kynurenine are important components of the host response to IAV infection.

Here we show that the IFN-mediated transcription of IDOI and production of kynurenine was upregulated in response to IAV infection in mouse lungs and human primary macrophages. However, IAV non-structural protein 1 (NS1) attenuated the expression of IFNs and IDOI, and several residues within the NS1 RNA/DNA-binding (RBD) and effector (ED) domains were implicated in this process. Furthermore, we demonstrated that inhibitors of IAV entry, but not of viral RNA transcription/replication, prevented the activation of IDOI expression and the production of kynurenine. Finally, we showed that KP was activated in response to herpes simplex virus (HSV) 1 and 2, and influenza B virus infections, as well as to E.coli lipopolysaccharides (LPS) stimulation. Based on these results, we conclude that metabolic reprogramming of KP could be a basic feature of different pathogen-host interactions, which should be taken into consideration during the antiviral/antibacterial drug development process.

This article is protected by copyright. All rights reserved. 


\section{Results}

IAV activates KP in mouse lungs

We performed recently transcriptomics experiment using RNA isolated from lung samples of A/WSN/1933(H1N1)- and mock-infected mice at day 3 post infection [24]. Our analysis identified many differentially expressed IFN genes (fold change (FC)>4 and <-4) and one gene, which belonged to the tryptophan metabolism according to the REACTOME pathway database (Fig. 2A). IDOI expression was upregulated more than eight folds in the lungs of all three IAV-infected animals (average $\mathrm{FC}=11.3 ; \mathrm{p}=5 \times 10^{-7}$ ). To test whether tryptophan metabolism was altered during IAV infection we analysed eight tryptophan metabolites in lung homogenates prepared from WSN- and mock-infected mice at day 3 post infection using LC-MS/MS [25]. We detected 7 metabolites, including tryptophan, kynurenine, kynurenic acid, 3-hydroxyanthranilic acid (3-HAA), 5hydroxytryptophan (5-HT), nicotinamide adenine dinucleotide (NAD), 5-hydroxyindole-3-acetic acid (5-HIAA; Fig. 2B). Importantly, only the level of kynurenine was significantly elevated in IAVinfected animals in comparison to the control group (average $\mathrm{FC}=6.2 ; \mathrm{p}=2 \times 10^{-9}$ ). Thus, WSN infection activated the IFN-mediated expression of IDOI and the production of kynurenine in mouse lungs, indicating that KP of tryptophan metabolism is a component of host responses during IAV infection.

IAV and several other viruses as well as bacterial LPS activate cellular KP in macrophages

The mammalian lung is composed of several cell types, from which alveolar macrophages, epithelial and dendritic cells represent the primary targets for IAV infection. Human peripheral blood mononuclear cells (PBMC)-derived macrophages represent a reliable model system for studying IAVhost cell interactions [26]. Macrophages isolated from healthy donors are susceptible to influenza $\mathrm{A}(\mathrm{H} 1 \mathrm{~N} 1)$ and $\mathrm{A}(\mathrm{H} 3 \mathrm{~N} 2)$ virus infection as could be judged from the cell viability assay (Fig. 3A). Our gene expression analysis indicated that infected cells overexpressed several IFN genes, including $I F N B I$ and $I F N G$ as well as IDOI (average $\mathrm{FC}=3.7$ ), but not other genes of KP (Fig. 3B). RT-qPCR analysis confirmed these results (Fig. 3C). Immunoblot analyses also showed that expression of IDOI, $I F N B 1$, as well as viral $M 1, N S 1$ and $N P$ was upregulated in infected cells (Fig. 3D).

In order to understand whether the KP was altered during IAV infection we analysed eight tryptophan metabolites in the macrophage culture medium at $24 \mathrm{~h}$ after IAV or mock infection. We found that the level of kynurenine was increased by around tenfold in response to IAV infection (average FC=9.8), whereas the level of kynurenic acid, tryptophan, 5-HT and NAD remained almost unaffected, and 3-HK, 3-HAA, and 5-HIAA were undetectable (Fig. 3E). Altogether, these results indicate that the IDOI expression and kynurenine production were upregulated in response to IAV infection in human primary macrophages.

We next tested whether infection with other viruses or stimulation with viral dsRNA, or bacterial LPS could activate the kynurenine biosynthesis in macrophages. We infected macrophages with influenza B, echovirus 6 (EV6), EV1, HSV1, HSV2 or treated them with bacterial LPS or viral dsRNA. Gene-expression analysis, followed by RT-qPCR as well as LC-MC/MC analysis showed that the expression of $I D O 1$ and kynurenine production was upregulated $\left(\mathrm{FC}_{I D O I}>2.6 ; \mathrm{FC}_{\text {kynurenine }}>2.8\right)$ in influenza B, HSV1 and HSV2 infected and LPS-stimulated cells, but not in EV1, EV2-infected or dsRNA-stimulated macrophages (Fig. 3B-D). In particular, IDO1 was expressed by a factor of $\sim 100$ (H1N1 and H3N2), 1000 (influenza B) or $\sim 100$ (HSV1 and HSV2) (Fig. 3C, top), while IFNB1 was overexpressed by a factor of $\sim 10000$ (H1N1 and H3N2), 30000 (influenza B), 1000 (EV1), or $\sim 5000$ (EV6, HSV1 and HSV2) (Fig. 3C, bottom). Interestingly, the expression of IFNG, IFNB1, as well as several IFNA genes, was also upregulated in these cells. Thus, our results suggest that kynurenine biosynthesis is upregulated in response to different IFN-stimulating agents.

\section{Specific IFNs activate KP in infected and non-infected cells}

Our gene expression experiments, as well as previous studies, indicated that IFN $\alpha$, IFN $\beta$, and IFN $\gamma$ might regulate IDOI-mediated KP [12, 14, 27]. Therefore, we tested the effect of different human recombinant IFNs on the transcription of IDOI and the production of kynurenine in

This article is protected by copyright. All rights reserved. 
macrophages (Fig. 4A-D). We observed that non-cytotoxic concentrations of IFN $\alpha-2 a$, IFN $\alpha-2 b$, IFN $\beta-1 \mathrm{a}$ and IFN $\beta-1 \mathrm{~b}$, and especially IFN $\gamma$, but not IFN $\Omega 1$, IFN $\lambda$ (IL28; IL29) upregulated the transcription of $I D O 1$ and the production of kynurenine in comparison with mock-infected cells $\left(\mathrm{FC}_{\text {IDOI }}>180 ; \mathrm{FC}_{\text {kynurenine }}>10\right)$ (Fig. $\left.4 \mathrm{C}, \mathrm{D}\right)$.

IFN $\alpha$ and IFN $\gamma$ are well-characterized stimuli of IDOI expression, by contrast to IFN $\beta[12,14]$. To confirm that IAV can activate IFN $\beta$-mediated KP, we silenced IFNBI for $24 \mathrm{~h}$ in human retinal pigment epithelial (RPE) cells and infected the cells with influenza $\mathrm{A}(\mathrm{H} 1 \mathrm{~N} 1)$ virus or mock (Fig. 5A). The cell viability of the silenced cells was measured 24 hours after infection (Fig. 5B). We also analysed $I F N B 1, I D O I$ and $M I$ expression at $8 \mathrm{hpi}$ and kynurenine production at 24 hpi. IFNB1silencing in H1N1-infected cells indeed reduced the expression of IFNB1 (by about seven folds) as well as that of $I D O 1$ (by about two fold) (Fig. 5C), resulting in attenuated KP (Fig. 5D). Interestingly, the expression of viral M1 (as expressed as copy number of viral M segment) was increased by about two fold in IFNBI-silenced cells, indicating that IFNB1 limited viral replication. Thus, IFNBI could regulate IDOI-mediated production of kynurenine.

We next tested whether IFNs secreted by infected cells can trigger the kynurenine production in non-infected cells. For this, we performed an experiment schematically depicted in Figure 6A. In particular, we collected media from IAV-infected macrophages (P1), neutralized IAVs with an antiHA antibody [28], diluted the media 20 fold and applied it to non-infected cells (P2). Cell viability assay, gene expression profiling and LC-MS/MS analysis showed that the media from infected P1 cells was not cytotoxic, but it induced the transcription of IDOI and production of kynurenine in noninfected $\mathrm{P} 2$ cells $\left(\mathrm{FC}_{I D O 1}>13 ; \mathrm{FC}_{\text {kynurenine }} \geq 13\right.$ ) (Fig. 6B, C, D). Interestingly, media from $\mathrm{P} 1$ cells also activated synthesis of 3-HAA and kynurenic acid in $\mathrm{P} 2$ cells $\left(\mathrm{FC}_{3-H A A}>56 ; \mathrm{FC}_{\text {kynurenic acid }} \geq 13\right)$. In the control experiment, we used media from P2 cells and treated non-infected P3 cells (Fig. 6D). There was no upregulation of kynurenine production in P3 cells. Thus, IDO1-modulators produced by IAVinfected cells stimulated KP both in infected and non-infected cells, i.e. they had both autocrine and paracrine activity.

\section{Inactivation of IAV NS1 exacerbate KP}

IAV suppresses the transcription of many IFN and IFN-stimulated genes (ISGs) through its multifunctional NS1 protein in infected cells (Fig. 7A) [29-33]. To understand whether NS1 can antagonize IFN-mediated transcription of IDOI and the production of kynurenine, we infected macrophages with different $\mathrm{A}(\mathrm{H} 1 \mathrm{~N} 1)$ strains expressing mutant or wild type NS1 protein. In particular, we used WSN strains with mutations in the RNA-binding domain (RBD, R38A/K41A), the effector domain (ED, F103S/M106I and A149V) or the C-terminal region ( $\Delta 221-230)$ of NS1 [30, 33, 34]. It was shown that these mutations prevent NS1 interactions with dsRNA/DNA, CPSF4, nuclear export machinery or some other cellular and viral factors, and thus suppress the production of IFNs and ISGs [30-33, 35]. Fig. 7B demonstrates that mutant viruses similarly to wild type strain reduced the viability of macrophages. However, infections with IAV strains that carry mutations in RBD or ED but not at the C-terminus of NS1, upregulated the expression of IDOI and the production of kynurenine in comparison to wild type virus (i.e. the upregulation of $I D O 1$ seems to be about tenfold for the first three mutants). The levels of $I F N B 1$, in contrast to viral $M 1$ were also upregulated by these strains (Fig. 7C, D). Thus, inactivation of viral IFN-antagonist NS1 exacerbated KP.

\section{Inhibition of viral replication prior to IFN induction limits KP activation}

Next, we tested the effect of five anti-IAV compounds (obatoclax, SNS-032, saliphenylhalamide (SaliPhe), gemcitabine and JNJ872) and two IDO1 inhibitors (epacadostat and NLG919), on IDO1 expression and kynurenine production in WSN- and mock infected macrophages [26, 33, 36-38]. A schematic representation of the experiment is depicted in Figure 8A. We found that obatoclax, SNS032, SaliPhe, gemcitabine and JNJ872, in contrast to epacadostat and NLG919 rescued IAV-infected cells from IAV-mediated death at noncytotoxic concentrations (Fig. 8B). Moreover, obatoclax, SNS032, and SaliPhe efficiently reduced IAV-induced transcription of both IFNBI and IDOI and production of kynurenine (Fig 8C, D). By contrast, IAV-induced transcription of both IFNBI and

This article is protected by copyright. All rights reserved. 
IDO1 remained unchanged upon JNJ-872 treatment, while gemcitabine slightly increased both of them. These results indicate that the antiviral compounds, which target the virus entry (such as obatoclax, SNS-032 and SaliPhe), and not those targeting later stages of the IAV replication cycle (such as gemcitabine and JNJ-872), may inhibit IAV-stimulated KP. As expected, both IDO1 inhibitors at non-cytotoxic concentrations allowed the transcription of IDOI, but not the synthesis of kynurenine, indicating that IDO1 is responsible for kynurenine production in IAV-infected human macrophages.

\section{Discussion}

In the present study, we have shown that IAV infection induced IFN-mediated expression of IDOI in human primary macrophages and mouse lungs. IDOI overexpression was associated with an increased kynurenine level. Given that kynurenine functions as an immuno- and neuromodulator, its production by IAV-infected cells could contribute to systemic responses of the host to the infection at hand.

We have also demonstrated that different IFNs, including IFN $\gamma$, IFN $\beta$, and IFN $\alpha$, played an important role in the activation of KP. However, IAV attenuated the IFN-mediated KP activation, notably through its NS1 protein. Indeed, substitutions that are known to alter the $I F N$-antagonistic activity of NS1 (R38A/K41A, F103S/M106I and A149V) resulted in overexpression of both IFNB1 and $I D O I$ and augmented the level of kynurenine. Thus, we have provided novel insight in the regulation of host responses and virus counter-responses in IAV-infected cells.

Moreover, we observed that the KP was activated in macrophages in response to infection with influenza B, HSV1, HSV2 strains or stimulation with bacterial LPS. Also other important human pathogens (such as, human immunodeficiency virus, hepatitis B virus, hepatitis $\mathrm{C}$ virus, cytomegalovirus, Chlamydia psittaci, Toxoplasma gondii, and Leishmania donovani) have been shown to activate KP in infected cells [39]. Thus, reprogramming of KP could be a basic mechanism uniting a surprisingly wide range of pathogen-host interactions.

We further demonstrated that antiviral compounds that inhibit IAV entry prevented KP activation. By contrast, antiviral agents that inhibited later stages of virus infection stimulated KP. Given that kynurenine has been reported to trigger pain hypersensitivity during viral infection [11], antivirals that inhibit IAV entry, as well as a combination of antivirals which inhibit later stages of IAV infection with IDOI inhibitors, might be used for treatment of severe IAV infections and accompanying neurological symptoms.

\section{Experimental procedures}

\section{Viruses and other immune stimuli}

Human influenza A/WSN/33(H1N1) strains expressing wild type (WT), R38A/K41A mutant or truncated NS1 $(\Delta 221-230)$ were generated using the WSN eight-plasmid-based reverse genetics system in HEK293T and Vero cells as described previously [25, 33, 40]. The recombinant A/WSN/33 viruses expressing F103S/M106I, A149V, or G224R/E229K NS1 mutants were generated using twelve-plasmid-based reverse genetics and were propagated in 11-day-old embryonated chicken eggs at $34^{\circ} \mathrm{C}$ for 3 days as previously described [25, 30, 41]. Human influenza A/Udorn/307/1972 (H3N2) virus was cultured in embryonated hen eggs as described previously [42]. Influenza B/Shandong/7/97 virus was grown in the allantoic cavities of 11-day-old embryonated chicken eggs for 3 days at $33^{\circ} \mathrm{C}$ as described [43]. EV1 (Farouk strain, obtained from the ATCC) was propagated in a monolayer of GMK cells and purified using an overall scheme similar to that described previously [44]. EV6 was propagated in a monolayer of A549 cells as described previously [45]. HSV-1 and -2 stocks were prepared from infected Vero cells as described earlier [46].

The titers of influenza A/WSN/1933 wild type and mutants strains were determined on MDCK cells by plaque assay [26]. Influenza A/Udorn/1972 titer was determined using plaque assay and hemagglutination assay as described [42]. Influenza B virus titer was determined by indirect immunofluorescence staining with a nucleoprotein (NP)-specific antibody as described previously

This article is protected by copyright. All rights reserved. 
[26]. EV1 and EV6 titers were determined by endpoint titration method described in [47]. HSV-1 and HSV-2 titers were determined by plaque titration in Vero cells in the presence of human immunoglobulin $\mathrm{G}(20 \mathrm{ug} / \mathrm{ml})$. Accordingly, viral titers were expressed as plaque-forming units (PFU) or fluorescence-forming units $(\mathrm{FFU}) / \mathrm{ml}$ or $50 \%$ tissue culture infective dose (TCID50), respectively. The virus stocks were stored at $-80{ }^{\circ} \mathrm{C}$.

Lyophilized LPS from Escherichia coli O55:B5 was from Sigma Aldrich (St. Louis, MO, USA). LPS was dissolved to $10 \mathrm{mg} / \mathrm{ml}$ in deionized sterile water. DsRNA molecules of 2948, 4063 and 6374 base pairs in size were isolated from purified Pseudomonas phage phi6 nucleocapsids as described [48]. Lyophilized recombinant human rh IFN-alpha $1 \mathrm{~b}$ (cat \#: 11343594 ; specific activity: $1.0 \times 10^{8}$ IU/mg), rh IFN-alpha 2a (cat \#: 11343504; specific activity 3.7 x $10^{8} \mathrm{IU} / \mathrm{mg}$ ), rh IFN-alpha $2 \mathrm{~b}$ (cat \#: 11343514; specific activity: $2.6 \times 10^{8} \mathrm{IU} / \mathrm{mg}$ ); rh IFN-beta 1a (cat \#: 11343520; specific activity: 2.7 x $10^{8} \mathrm{IU} / \mathrm{mg}$ ), rh IFN-beta $1 \mathrm{~b}$ (cat \#: 11343542 ; specific activity: $3.2 \times 10^{7} \mathrm{IU} / \mathrm{mg}$ ), rh IFN-gamma (cat \#: 11343534; specific activity: 2 x $10^{7} \mathrm{IU} / \mathrm{mg}$ ), rh IFNW1 (cat \#: 11344784; specific activity: < $0.01 \mathrm{ng} / \mathrm{ml}$ ), rh IL-28A (cat \#: 11340280; specific activity: not specified), and rh IL-29 (cat \#: 11340290; specific activity: not specified were from ImmunoTools, Germany. IFNs were dissolved in deionized sterile water to obtain $100 \mu \mathrm{g} / \mathrm{ml}$ concentrations. The reagents were stored at $-80{ }^{\circ} \mathrm{C}$.

\section{Antiviral agents, IDO inhibitors and siRNAs}

Saliphenylhalamide (SaliPhe) was synthesized as described in [49]. Obatoclax, gemcitabine, SNS032, epacadostat and NLG919 were from Selleck Chemicals, USA. JNJ872 was from Janssen, USA. Compounds were dissolved in $100 \%$ dimethyl sulfoxide (Sigma-Aldrich) to obtain $10 \mathrm{mM}$ stock solutions and stored at $-80^{\circ} \mathrm{C}$. Pan $\mathrm{H} 1 \mathrm{~N} 1$ neutralizing $\mathrm{HA}$ antibody $(6 \mathrm{~F} 12)$ was produced as described in [28]. siGenome SMARTpool siRNA (siIFNB1; cat \#: M-019656-01, sequence: 5'GGAAUGAGACUAUUGUUGA-3', 5'-CAACAAGUGUCUCCUCCAA-3', 5'UGGCUAAUGUCUAUCAUCA-3'; 5'-GCUAAUGUACUGCAUAUGA-3' and ON-TARGETplus non-targeting control siRNA (cat \#: D-001810-10; sequence: 5'-UGGUUUACAUGUCGACUAA-3', 5'-UGGUUUACAUGUUGUGUGA-3', 5'-UGGUUUACAUGUUUUCUGA-3', 5'UGGUUUACAUGUUUUCCUA-3') were from Dharmacon, USA.

\section{Cells}

Human primary macrophages were obtained from leukocyte-rich buffy coats from healthy blood donors under permission from the Finnish Red Cross Blood Transfusion Service and the University of Helsinki Central Hospital, Finland (165/13/03/00/2011). The experiments were undertaken with the understanding and written consent of each subject. Monocytes were isolated and differentiated into macrophages as described previously [50]. Monocytes were seeded on 96- or 6-well plates and cultured in serum free macrophage media (Gibco) supplemented with $10 \mathrm{ng} / \mathrm{ml}$ granulocyte macrophage colony stimulating factor (GM-CSF; Biosource International) and $50 \mathrm{U} / \mathrm{mL}$ penicillinstreptomycin (Lonza) at $37^{\circ} \mathrm{C}$ and $5 \% \mathrm{CO} 2$ for 7 days. The media was replaced with fresh GM-CSFfree macrophage media before the macrophages were infected with or stimulated. Viral infections were carried out under BSL-2 conditions and in compliance with regulations of the University of Helsinki (permit No 21/M/09).

Human RPE cells which represent excellent model system of IAV-host cell interaction were grown in DMEM-F12 medium supplemented with $50 \mathrm{U} / \mathrm{ml}$ PenStrep, 2mM L-glutamine, $10 \%$ FBS, and $0,25 \%$ sodium bicarbonate (Sigma-Aldrich) [26]. The cells were propagated at $37{ }^{\circ} \mathrm{C}$ in $5 \% \mathrm{CO}_{2}$. RPE cells were cultured to $80 \%$ confluency in 24 well plates and transfected with $100 \mathrm{nM}$ specific or control siRNA using Lipofectamine ${ }^{\circledR}$ RNAiMAX Reagent (Thermo Fisher Scientific). Twenty-four hours after transfections, the cells were infected with WSN or mock using virus growth medium (VGM) containing 0.2\% BSA (Sigma-Aldrich), $2 \mathrm{mM} \mathrm{L-glutamine,} 0.348 \% \mathrm{NaHCO} 3$ and $1 \mu \mathrm{g} / \mathrm{ml} \mathrm{l-}$ 1-tosylamido-2-phenylethyl chloromethyl ketone-trypsin (TPCK)-trypsin (Sigma-Aldrich) in DMEMF12. Ten hours after infection, the levels of genes of interest were analysed using RT-qPCRs.

This article is protected by copyright. All rights reserved. 


\section{Cell viability and compound efficacy assay}

The cell viability and compound efficacy were analysed with the Cell Titer Glo assay (CTG; Promega) at $24 \mathrm{hpi}$ as descried previously $[26,33,36]$. The $50 \%$ cytotoxic concentrations $\left(\mathrm{CC}_{50}\right)$ and the half maximal effective concentrations $\left(\mathrm{EC}_{50}\right)$ for obatoclax, SNS-032, SaliPhe, gemcitabine and JNJ-872 were reported previously $[26,33,36]$. The CC50 and EC50 values for epacadostat were $10 \mu \mathrm{M}$ and $>30 \mu \mathrm{M}$, and for NLG919 were $5 \mu \mathrm{M}$ and $>30 \mu \mathrm{M}$, respectively.

\section{Gene expression profiling and reverse-transcription quantitative polymerase chain reaction (RT-qPCR)}

We analyzed the gene expression data from this or our previous studies (GEO accession numbers: GSE79854, GSE62127, GSE66015, GSE65699; ArrayExpress accession number: E-MTAB-4891) $[24-26,33,35,36]$. In those studies, the total RNA was extracted from infected macrophages $8 \mathrm{~h}$ post infection or from infected mice $3 \mathrm{~d}$ post infection. Human and mice gene expression analyses were performed using Illumina HumanHT-12 V4.0 or Agilent's 4×44K (G4122F) whole mouse genome microarray kits, respectively. The data analysis was performed using $\mathrm{R}$ (version 3.2.2) and $\mathrm{R}$ studio (Version 0.99.486). Raw Illumina transcriptomics data was normalized using quantile normalization with normalize.quantiles function from Bioconductor's preprocessCore package (www.bioconductor.org/packages//2.7/bioc/html/preprocessCore.html). The data was $\log 2$ transformed. Differential expression analysis of the normalized data was performed using the LIMMA package implemented in Bioconductor by employing an empirical Bayes t-test (Ritchie et al., 2015). Infections/treatments were indicated in the design matrix for the linear fitting. The BenjaminiHochberg method was used to adjust p-values for multiple hypothesis testing. Heatmap for transcriptomics data was generated using the pheatmap package (https://cran.rproject.org/web/packages/pheatmap/index.html) based on $\log 2$ transformed expression data and hierarchical clustering of genes and samples in the heatmap was generated using the complete-linkage clustering method and Euclidian distances. Genes from tryptophan metabolism were derived from REACTOME database (www.reactome.org/).

RT-qPCR was performed with the ABI PRISM 7500 Sequence Detection System (Applied Biosystems) using Fast SYBR Green Master Mix (Applied Biosystems). IAV MI (forward primer: 5'GACCRATCCTGTCACCTCTGAC-3' and reverse primer: 5'AGGGCATTYTGGACAAAKCGTCTA-3', Sigma-Aldrich) (www.who.int/csr/resources/publications/swineflu/realtimeptpcr/en/index.html), cellular GAPDH (forward primer: 5'-GGCTGGGGCTCATTTGCAGGG-3' and reverse primer: 5'TGACCTTGGCCAGGGGTGCT-3', Oligomer Oy), cellular IDO1 (forward primer: 5'GAAAGGTCATGGAGATGTCC-3', and reverse primer: 5'-CAACCAATAGAGAGACCAGG-3'; Sigma-Aldrich), and IFNB1 (forward: 5'-GCCGCATTGACCATCTATGA-3' and reverse: 5'GCCAGGAGGTTCTCAACAATAG-3', Applied Biosystems) were analyzed. Technical triplicates of each sample were performed on the same qPCR plate and non-templates and non-reverse transcriptase samples were analyzed as negative controls. The relative gene expression was analysed as described previously [33] and the results were presented as relative units (RU). The data was $\log 2$ transformed and t-test was used to calculate fold changes and p-values for differentially expressed genes. The Benjamini-Hochberg method was used for p-value adjustments.

\section{Immunoblotting}

For immunoblot analysis, macrophages were infected with influenza A/Udorn/1933 virus at MOI 1. At different time points post infection, the media was removed; cells were lysed in $2 \times$ SDS-sample buffer, and sonicated to dissolve aggregates. Proteins were resolved by electrophoresis in gradient 4 $20 \%$ SDS-PAGE gels (Biorad) and transferred to polyvinylidene fluoride membrane (GE Healthcare). Membranes were blocked with 5\% BSA (Sigma-Aldrich) in Tris-buffered saline (TBS) for $1 \mathrm{~h}$ at room temperature and incubated with primary rabbit anti-NS1 (1:5000; from I. J. laboratory) rabbit anti-NP (1:5000; from I. J. laboratory), rabbit anti-IDO (1:1000; Cell Signaling \#12006), or rabbit anti-GAPDH (1:1000; Santa Cruz, sc-47724) antibody over-night at $+4{ }^{\circ} \mathrm{C} .$. Membranes were washed three times for 10 min with TBS buffer containing 0.5\% Tween 20 (Tween/TBS) and incubated for 1

This article is protected by copyright. All rights reserved. 
$\mathrm{h}$ at room temperature with secondary antibodies. After three washes for $10 \mathrm{~min}$ with Tween/TBS buffer and one with TBS, membranes were scanned on an Odyssey scanner (Li-Cor Biosciences).

\section{Mouse experiments}

In the present study, we used mouse lungs which were prepared as described in [24, 25]. Briefly, 6-8 weeks old female BALB/c mice (altogether 9 mice per group) were challenged with influenza $\mathrm{A} / \mathrm{WSN} / 1933(\mathrm{H} 1 \mathrm{~N} 1)$ virus $\left(0.5 \mathrm{LD} 50\right.$ or $\left.1.5 \times 10^{5} \mathrm{PFU}\right)$ or mock infections. Three days after infection, the mice were sacrificed and lungs were collected. Total RNA was isolated from the lungs of 3 WSNand 3 mock-infected mice using the Qiagen Rneasy kit (Qiagen). Lung homogenates were prepared from similarly infected $6 \mathrm{WSN}$ - and 6 mock-infected mice and stored at $-80^{\circ} \mathrm{C}$. Mouse experiments were carried out under BSL-2+ conditions in compliance with European animal welfare regulations. The protocols were approved by the Animal Care and Use Committee at CRJ under relevant institutional (DSV, permit number: 7827), and by the Institutional Ethics Committee on Experimental Animals of the VIB Department for Molecular Biomedical Research at Ghent University.

\section{Metabolomics analysis}

Metabolomics analysis was performed as described previously [36]. Briefly, $10 \mu \mathrm{L}$ of labelled internal standard mixture was added to $100 \mu \mathrm{L}$ of the sample (macrophage media, cell lysates or mouse lung homogenates). $0.4 \mathrm{~mL}$ of solvent (99\% ACN and 1\% FA) was added to each sample. Insoluble fraction was removed by centrifugation $\left(14000 \mathrm{rpm}, 15 \mathrm{~min}, 4^{\circ} \mathrm{C}\right)$. The extracts were dispensed in Ostro ${ }^{\mathrm{TM}}$ 96-well plate (Waters Corporation, Milford, USA) and filtered by applying vacuum at a delta pressure of 300-400 mbar for 2.5 min on Hamilton StarLine robot's vacuum station. The clean extract was collected to a 96-well collection plate, placed under the Ostro ${ }^{\mathrm{TM}}$ plate. The collection plate was sealed and centrifuged for $15 \mathrm{~min}, 4000 \mathrm{rpm}, 4^{\circ} \mathrm{C}$ and placed in auto-sampler of the liquid chromatography system for the injection. Sample analysis was performed on an Acquity UPLC-MS/MS system (Waters Corporation, Milford, MA, USA). The auto-sampler was used to perform partial loop with needle overfill injections for the samples and standards. The detection system, a Xevo® TQ-S tandem triple quadrupole mass spectrometer (Waters, Milford, MA, USA), was operated in both positive and negative polarities with a polarity switching time of $20 \mathrm{msec}$. Electro spray ionization (ESI) was chosen as the ionization mode with a capillary voltage at $0.6 \mathrm{KV}$ in both polarities. The source temperature and desolvation temperature of $120^{\circ} \mathrm{C}$ and $650^{\circ} \mathrm{C}$, respectively, were maintained constantly throughout the experiment. Declustering potential (DP) and collision energy (CE) were optimized for each compound. Multiple Reaction Monitoring (MRM) acquisition mode was selected for quantification of metabolites with individual span time of $0.1 \mathrm{sec}$ given in their individual MRM channels. The dwell time was calculated automatically by the software based on the region of the retention time window, number of MRM functions and also depending on the number of data points required to form the peak. MassLynx 4.1 software was used for data acquisition, data handling and instrument control. Data processing was done using TargetLynx software and metabolites were quantified by calculating curve area ratio using labeled internal standards (IS) (area of metabolites/area of IS) and external calibration curves. Metabolomics data was $\log 2$ transformed for linear modelling and empirical-Bayes-moderated t-tests using the LIMMA package [51]. To analyse the differences in metabolites levels, a linear model was fit to each metabolite. The Benjamini-Hochberg method was used to correct for multiple testing. The significant metabolites were determined at a Benjamini-Hochberg false discovery rate (FDR) controlled at $10 \%$. The heatmap for all the metabolites was generated using the pheatmap package (https://cran.rproject.org/web/packages/pheatmap/index.html) based on $\log 2$ transformed profiling data. REACTOME pathway analysis tool was used to retrieve Trp metabolites (www.reactome.org/).

\section{Acknowledgments}

We thank Paivi Castren-Kortekangas and Jan Roelof Van Der Meer from Janssen Pharmaceuticals for providing JNJ872 and for the critical reading of the manuscript. We also thank Robert Webster for influenza A/WSN/1933 reverse genetic systems. This study was supported by J\&A Erkko foundation (to DEK), Erasmus fellowship (to LG), Orion Research Foundation (to VV), and University of

This article is protected by copyright. All rights reserved. 
Helsinki three-year research grant (No. 465/51/2014, to DK) and Robert A. Welch Foundation (grant I-1422, to JDB) .

\section{Author contributions}

LG, SS, AB, VV and DK designed research; LG, SS, YF, JN, BS, AB, JT, and LVG performed research; LVG, RLG, MSM, VM, JDB, SM, TAN, XS, MBL, MK, HP, VH and IJ contributed new reagents or analytic tools; LG, SS, YF, JN, VV, RLG and DK analysed data; all authors wrote the paper.

\section{References}

1. Mortality, G. B. D. \& Causes of Death, C. (2015) Global, regional, and national age-sex specific all-cause and cause-specific mortality for 240 causes of death, 1990-2013: a systematic analysis for the Global Burden of Disease Study 2013, Lancet. 385, 117-71.

2. Iwasaki, A. \& Pillai, P. S. (2014) Innate immunity to influenza virus infection, Nat Rev Immunol. 14, 315-28.

3. Soderholm, S., Fu, Y., Gaelings, L., Belanov, S., Yetukuri, L., Berlinkov, M., Cheltsov, A. V., Anders, S., Aittokallio, T., Nyman, T. A., Matikainen, S. \& Kainov, D. E. (2016) Multi-Omics Studies towards Novel Modulators of Influenza A Virus-Host Interaction, Viruses. 8, pii: E269.

4. Cui, L., Zheng, D., Lee, Y. H., Chan, T. K., Kumar, Y., Ho, W. E., Chen, J. Z., Tannenbaum, S. R. \& Ong, C. N. (2016) Metabolomics Investigation Reveals Metabolite Mediators Associated with Acute Lung Injury and Repair in a Murine Model of Influenza Pneumonia, Sci Rep. 6, 26076.

5. Tisoncik-Go, J., Gasper, D. J., Kyle, J. E., Eisfeld, A. J., Selinger, C., Hatta, M., Morrison, J., Korth, M. J., Zink, E. M., Kim, Y. M., Schepmoes, A. A., Nicora, C. D., Purvine, S. O., Weitz, K. K., Peng, X., Green, R. R., Tilton, S. C., Webb-Robertson, B. J., Waters, K. M., Metz, T. O., Smith, R. D., Kawaoka, Y., Suresh, M., Josset, L. \& Katze, M. G. (2016) Integrated Omics Analysis of Pathogenic Host Responses during Pandemic H1N1 Influenza Virus Infection: The Crucial Role of Lipid Metabolism, Cell Host Microbe. 19, 254-66.

6. Bajwa, G., DeBerardinis, R. J., Shao, B., Hall, B., Farrar, J. D. \& Gill, M. A. (2016) Cutting Edge: Critical Role of Glycolysis in Human Plasmacytoid Dendritic Cell Antiviral Responses, $J$ Immunol. 196, 2004-9.

7. Tam, V. C., Quehenberger, O., Oshansky, C. M., Suen, R., Armando, A. M., Treuting, P. M., Thomas, P. G., Dennis, E. A. \& Aderem, A. (2013) Lipidomic profiling of influenza infection identifies mediators that induce and resolve inflammation, Cell. 154, 213-27.

8. Morita, M., Kuba, K., Ichikawa, A., Nakayama, M., Katahira, J., Iwamoto, R., Watanebe, T., Sakabe, S., Daidoji, T., Nakamura, S., Kadowaki, A., Ohto, T., Nakanishi, H., Taguchi, R., Nakaya, T., Murakami, M., Yoneda, Y., Arai, H., Kawaoka, Y., Penninger, J. M., Arita, M. \& Imai, Y. (2013) The lipid mediator protectin D1 inhibits influenza virus replication and improves severe influenza, Cell. 153, 112-25.

9. Lu, C., Jiang, Z., Fan, X., Liao, G., Li, S., He, C., Han, L., Luo, S., Liu, Y., Lin, H., Li, L., Li, X., Liang, Q., Wang, Y. \& Luo, G. (2012) A metabonomic approach to the effect evaluation of treatment in patients infected with influenza A (H1N1), Talanta. 100, 51-6.

10. Dudek, S. E., Nitzsche, K., Ludwig, S. \& Ehrhardt, C. (2016) Influenza A viruses suppress cyclooxygenase-2 expression by affecting its mRNA stability, Sci Rep. 6, 27275.

11. Huang, L., Ou, R., Rabelo de Souza, G., Cunha, T. M., Lemos, H., Mohamed, E., Li, L., Pacholczyk, G., Randall, J., Munn, D. H. \& Mellor, A. L. (2016) Virus Infections Incite Pain Hypersensitivity by Inducing Indoleamine 2,3 Dioxygenase, PLoS pathogens. 12, e1005615.

12. Fox, J. M., Crabtree, J. M., Sage, L. K., Tompkins, S. M. \& Tripp, R. A. (2015) Interferon Lambda Upregulates IDO1 Expression in Respiratory Epithelial Cells After Influenza Virus Infection, J Interferon Cytokine Res. 35, 554-62.

13. Gold, E. S., Diercks, A. H., Podolsky, I., Podyminogin, R. L., Askovich, P. S., Treuting, P. M. \& Aderem, A. (2014) 25-Hydroxycholesterol acts as an amplifier of inflammatory signaling, Proceedings of the National Academy of Sciences of the United States of America. 111, 10666-71.

14. Taylor, M. W. \& Feng, G. S. (1991) Relationship between interferon-gamma, indoleamine 2,3dioxygenase, and tryptophan catabolism, FASEB J. 5, 2516-22.

This article is protected by copyright. All rights reserved. 
15. Stone, T. W. \& Darlington, L. G. (2002) Endogenous kynurenines as targets for drug discovery and development, Nat Rev Drug Discov. 1, 609-20.

16. King, N. J. \& Thomas, S. R. (2007) Molecules in focus: indoleamine 2,3-dioxygenase, Int J Biochem Cell Biol. 39, 2167-72.

17. Huang, L., Li, L., Klonowski, K. D., Tompkins, S. M., Tripp, R. A. \& Mellor, A. L. (2013) Induction and role of indoleamine 2,3 dioxygenase in mouse models of influenza a virus infection, PLoS One. 8, e66546.

18. Ohyama, K., Sano, T. \& Toyoda, H. (2004) Predominant contribution of IFN-beta expression to apoptosis induction in human uterine cervical fibroblast cells by influenza-virus infection, Biol Pharm Bull. 27, 1750-7.

19. Fox, J. M., Sage, L. K., Poore, S., Johnson, S., Tompkins, S. M. \& Tripp, R. A. (2014) Drug analog inhibition of indoleamine 2,3-dioxygenase (IDO) activity modifies pattern recognition receptor expression and proinflammatory cytokine responses early during influenza virus infection, J Leukoc Biol. 96, 447-52.

20. van der Sluijs, K. F., Nijhuis, M., Levels, J. H., Florquin, S., Mellor, A. L., Jansen, H. M., van der Poll, T. \& Lutter, R. (2006) Influenza-induced expression of indoleamine 2,3-dioxygenase enhances interleukin-10 production and bacterial outgrowth during secondary pneumococcal pneumonia, The Journal of infectious diseases. 193, 214-22.

21. Rytelewski, M., Meilleur, C. E., Yekta, M. A., Szabo, P. A., Garg, N., Schell, T. D., Jevnikar, A. M., Sharif, S., Singh, B. \& Haeryfar, S. M. (2014) Suppression of immunodominant antitumor and antiviral CD8+ T cell responses by indoleamine 2,3-dioxygenase, PLoS One. 9, e90439.

22. Fox, J. M., Sage, L. K., Huang, L., Barber, J., Klonowski, K. D., Mellor, A. L., Tompkins, S. M. \& Tripp, R. A. (2013) Inhibition of indoleamine 2,3-dioxygenase enhances the T-cell response to influenza virus infection, The Journal of general virology. 94, 1451-61.

23. Liu, X. C., Holtze, M., Powell, S. B., Terrando, N., Larsson, M. K., Persson, A., Olsson, S. K., Orhan, F., Kegel, M., Asp, L., Goiny, M., Schwieler, L., Engberg, G., Karlsson, H. \& Erhardt, S. (2014) Behavioral disturbances in adult mice following neonatal virus infection or kynurenine treatment--role of brain kynurenic acid, Brain Behav Immun. 36, 80-9.

24. Le Goffic, R., Leymarie, O., Chevalier, C., Rebours, E., Da Costa, B., Vidic, J., Descamps, D., Sallenave, J. M., Rauch, M., Samson, M. \& Delmas, B. (2011) Transcriptomic analysis of host immune and cell death responses associated with the influenza A virus PB1-F2 protein, PLoS pathogens. 7, e1002202.

25. Anastasina, M., Schepens, B., Soderholm, S., Nyman, T. A., Matikainen, S., Saksela, K., Saelens, X. \& Kainov, D. E. (2015) The C terminus of NS1 protein of influenza A/WSN/1933(H1N1) virus modulates antiviral responses in infected human macrophages and mice, J Gen Virol. 96, 2086-91.

26. Denisova, O. V., Kakkola, L., Feng, L., Stenman, J., Nagaraj, A., Lampe, J., Yadav, B., Aittokallio, T., Kaukinen, P., Ahola, T., Kuivanen, S., Vapalahti, O., Kantele, A., Tynell, J., Julkunen, I., Kallio-Kokko, H., Paavilainen, H., Hukkanen, V., Elliott, R. M., De Brabander, J. K., Saelens, X. \& Kainov, D. E. (2012) Obatoclax, saliphenylhalamide, and gemcitabine inhibit influenza a virus infection, J Biol Chem. 287, 35324-32.

27. Guillemin, G. J., Kerr, S. J., Pemberton, L. A., Smith, D. G., Smythe, G. A., Armati, P. J. \& Brew, B. J. (2001) IFN-beta1b induces kynurenine pathway metabolism in human macrophages: potential implications for multiple sclerosis treatment, J Interferon Cytokine Res. 21, 1097-101.

28. Tan, G. S., Krammer, F., Eggink, D., Kongchanagul, A., Moran, T. M. \& Palese, P. (2012) A pan-H1 anti-hemagglutinin monoclonal antibody with potent broad-spectrum efficacy in vivo, Journal of virology. 86, 6179-88.

29. Hale, B. G., Randall, R. E., Ortin, J. \& Jackson, D. (2008) The multifunctional NS1 protein of influenza A viruses, The Journal of general virology. 89, 2359-76.

30. Tynell, J., Melen, K. \& Julkunen, I. (2014) Mutations within the conserved NS1 nuclear export signal lead to inhibition of influenza A virus replication, Virology journal. 11, 128.

31. Jackson, D., Hossain, M. J., Hickman, D., Perez, D. R. \& Lamb, R. A. (2008) A new influenza virus virulence determinant: the NS1 protein four C-terminal residues modulate pathogenicity, Proceedings of the National Academy of Sciences of the United States of America. 105, 4381-6.

This article is protected by copyright. All rights reserved. 
32. Li, Z., Jiang, Y., Jiao, P., Wang, A., Zhao, F., Tian, G., Wang, X., Yu, K., Bu, Z. \& Chen, H. (2006) The NS1 gene contributes to the virulence of H5N1 avian influenza viruses, Journal of virology. 80, 11115-23.

33. Soderholm, S., Anastasina, M., Islam, M. M., Tynell, J., Poranen, M. M., Bamford, D. H., Stenman, J., Julkunen, I., Sauliene, I., De Brabander, J. K., Matikainen, S., Nyman, T. A., Saelens, X. \& Kainov, D. (2016) Immuno-modulating properties of saliphenylhalamide, SNS-032, obatoclax, and gemcitabine, Antiviral Res. 126, 69-80.

34. Kochs, G., Garcia-Sastre, A. \& Martinez-Sobrido, L. (2007) Multiple anti-interferon actions of the influenza A virus NS1 protein, $J$ Virol. 81, 7011-21.

35. Anastasina, M., Le May, N., Bugai, A., Fu, Y., Soderholm, S., Gaelings, L., Ohman, T., Tynell, J., Kyttanen, S., Barboric, M., Nyman, T. A., Matikainen, S., Julkunen, I., Butcher, S. J., Egly, J. M. \& Kainov, D. E. (2016) Influenza virus NS1 protein binds cellular DNA to block transcription of antiviral genes, Biochim Biophys Acta. 1859, 1440-1448.

36. Fu, Y., Gaelings, L., Soderholm, S., Belanov, S., Nandania, J., Nyman, T. A., Matikainen, S., Anders, S., Velagapudi, V. \& Kainov, D. E. (2016) JNJ872 inhibits influenza A virus replication without altering cellular antiviral responses, Antiviral Res. 133, 23-31.

37. Jochems, C., Fantini, M., Fernando, R. I., Kwilas, A. R., Donahue, R. N., Lepone, L. M., Grenga, I., Kim, Y. S., Brechbiel, M. W., Gulley, J. L., Madan, R. A., Heery, C. R., Hodge, J. W., Newton, R., Schlom, J. \& Tsang, K. Y. (2016) The IDO1 selective inhibitor epacadostat enhances dendritic cell immunogenicity and lytic ability of tumor antigen-specific T cells, Oncotarget.

38. Soderholm, S., Kainov, D. E., Ohman, T., Denisova, O. V., Schepens, B., Kulesskiy, E., Imanishi, S. Y., Corthals, G., Hintsanen, P., Aittokallio, T., Saelens, X., Matikainen, S. \& Nyman, T. A. (2016) Phosphoproteomics to characterize host response during influenza A virus infection of human macrophages, Mol Cell Proteomics.

39. Mehraj, V. \& Routy, J. P. (2015) Tryptophan Catabolism in Chronic Viral Infections: Handling Uninvited Guests, Int J Tryptophan Res. 8, 41-8.

40. Hoffmann, E., Neumann, G., Kawaoka, Y., Hobom, G. \& Webster, R. G. (2000) A DNA transfection system for generation of influenza A virus from eight plasmids, Proceedings of the National Academy of Sciences of the United States of America. 97, 6108-13.

41. Neumann, G., Watanabe, T., Ito, H., Watanabe, S., Goto, H., Gao, P., Hughes, M., Perez, D. R., Donis, R., Hoffmann, E., Hobom, G. \& Kawaoka, Y. (1999) Generation of influenza A viruses entirely from cloned cDNAs, Proceedings of the National Academy of Sciences of the United States of America. 96, 9345-50.

42. Lietzen, N., Ohman, T., Rintahaka, J., Julkunen, I., Aittokallio, T., Matikainen, S. \& Nyman, T. A. (2011) Quantitative subcellular proteome and secretome profiling of influenza A virus-infected human primary macrophages, PLoS pathogens. 7, e1001340.

43. Schneider, J., Dauber, B., Melen, K., Julkunen, I. \& Wolff, T. (2009) Analysis of influenza B Virus NS1 protein trafficking reveals a novel interaction with nuclear speckle domains, Journal of virology. 83, 701-11.

44. Ruokola, P., Dadu, E., Kazmertsuk, A., Hakkanen, H., Marjomaki, V. \& Ihalainen, J. A. (2014) Raman spectroscopic signatures of echovirus 1 uncoating, Journal of virology. 88, 8504-13.

45. Smura, T., Kakkola, L., Blomqvist, S., Klemola, P., Parsons, A., Kallio-Kokko, H., SavolainenKopra, C., Kainov, D. E. \& Roivainen, M. (2013) Molecular evolution and epidemiology of echovirus 6 in Finland, Infect Genet Evol. 16, 234-47.

46. Kakkola, L., Denisova, O. V., Tynell, J., Viiliainen, J., Ysenbaert, T., Matos, R. C., Nagaraj, A., Ohman, T., Kuivanen, S., Paavilainen, H., Feng, L., Yadav, B., Julkunen, I., Vapalahti, O., Hukkanen, V., Stenman, J., Aittokallio, T., Verschuren, E. W., Ojala, P. M., Nyman, T., Saelens, X., Dzeyk, K. \& Kainov, D. E. (2013) Anticancer compound ABT-263 accelerates apoptosis in virus-infected cells and imbalances cytokine production and lowers survival rates of infected mice, Cell Death Dis. 4, e742.

47. Biacchesi, S., Skiadopoulos, M. H., Yang, L., Murphy, B. R., Collins, P. L. \& Buchholz, U. J. (2005) Rapid human metapneumovirus microneutralization assay based on green fluorescent protein expression, J Virol Methods. 128, 192-7.

This article is protected by copyright. All rights reserved. 
48. Romanovskaya, A., Sarin, L. P., Bamford, D. H. \& Poranen, M. M. (2013) High-throughput purification of double-stranded RNA molecules using convective interaction media monolithic anion exchange columns, J Chromatogr A. 1278, 54-60.

49. Lebreton, S., Jaunbergs, J., Roth, M. G., Ferguson, D. A. \& De Brabander, J. K. (2008) Evaluating the potential of vacuolar ATPase inhibitors as anticancer agents and multigram synthesis of the potent salicylihalamide analog saliphenylhalamide, Bioorg Med Chem Lett. 18, 5879-83.

50. Pirhonen, J., Sareneva, T., Kurimoto, M., Julkunen, I. \& Matikainen, S. (1999) Virus infection activates IL-1 beta and IL-18 production in human macrophages by a caspase-1-dependent pathway, J Immunol. 162, 7322-9.

51. Smyth, G. K. (2004) Linear models and empirical bayes methods for assessing differential expression in microarray experiments, Stat Appl Genet Mol Biol. 3, Article3.

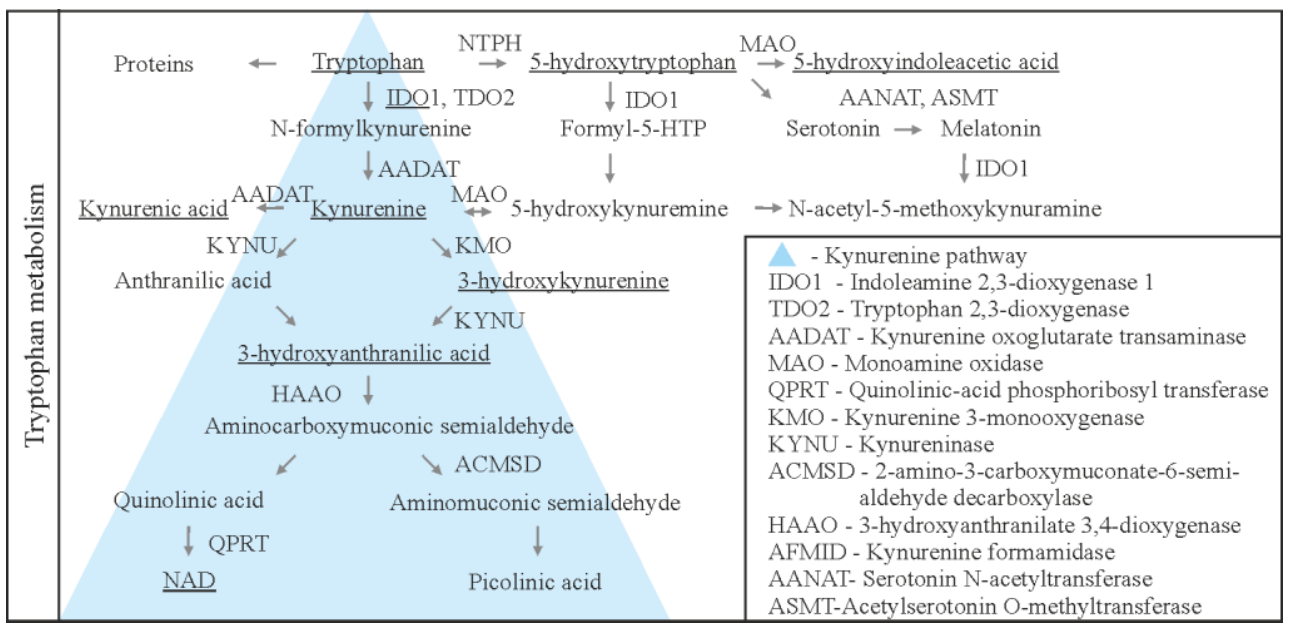

Fig. 1. Simplified schematic diagram depicting the tryptophan metabolism and KP. The enzymes that comprise the tryptophan metabolism are abbreviated in capital letters and listed in the insert. Metabolites and enzymes implicated in the present study are underlined. 
A

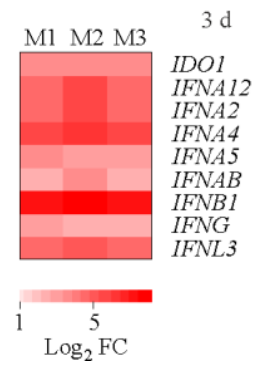

$\mathrm{B}$

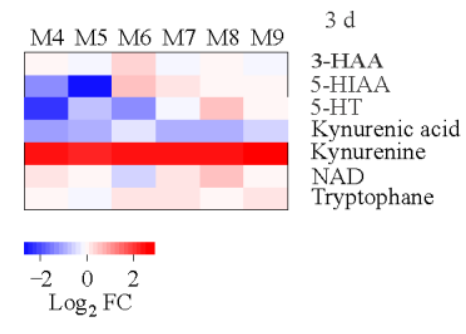

Fig. 2. KP is activated in mouse lungs in response to IAV infection. A. Six 6-8 weeks old female $\mathrm{BALB} / \mathrm{c}$ mice (3 per group) were challenged with influenza A/WSN/1933(H1N1) virus $\left(1.5 \times 10^{5}\right.$ $\mathrm{PFU}$ ) or mock infection for 3 days. The mice were sacrificed and lungs were collected. Total RNA was isolated and subjected to whole-genome gene expression analysis. A heatmap of variable IFN and $\mathrm{KP}$ genes affected by IAV infection is shown ( $\log 2 \mathrm{FC}>2, \mathrm{p}<0.05$, T-test). Rows represent gene symbols, columns represent samples. Each cell is coloured according to the log2-transformed and quantile-normalized expression values of the samples, expressed as FC relative to the average of mock controls. B. Twelve 6-8 weeks old female BALB/c mice (6 per group) were challenged with influenza A/WSN/1933(H1N1) virus (0,5 LD50) or mock infection for 3 days. The mice were sacrificed and the lungs were collected. Lungs were homogenized in PBS and 8 metabolites related to tryptophan metabolism were analysed using LC-MS/MS. Seven metabolites were detected in the lung homogenates of mock and WSN-infected animals. A heatmap of seven metabolites is shown. Rows represent metabolites, columns represent samples. Each cell is coloured according to the $\log 2-$ transformed and quantile-normalized values of the samples, expressed as FC relative to the average of mock controls. 
A

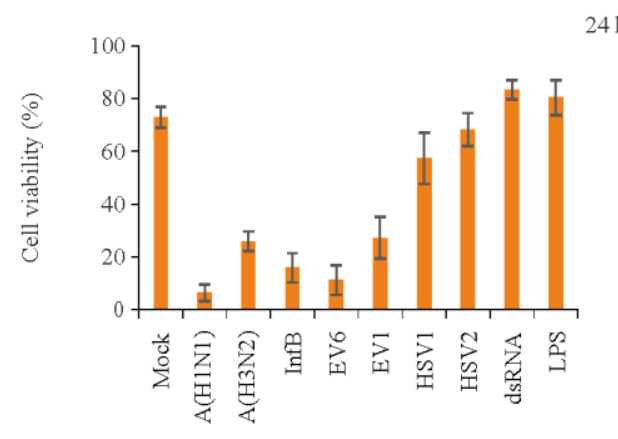

C
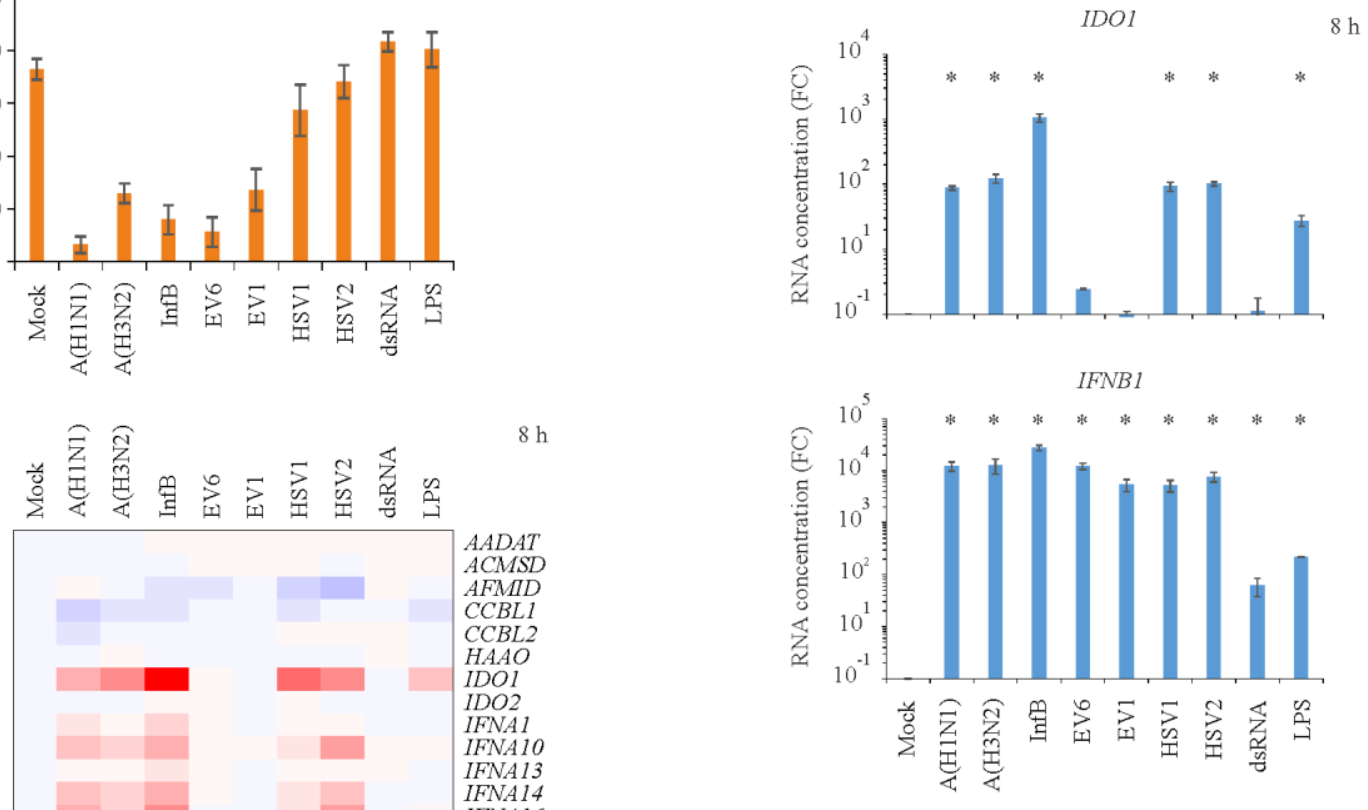

$\mathrm{D}$

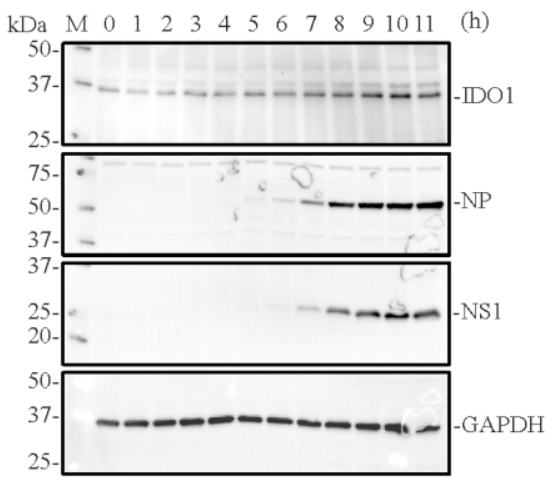

$\mathrm{E}$

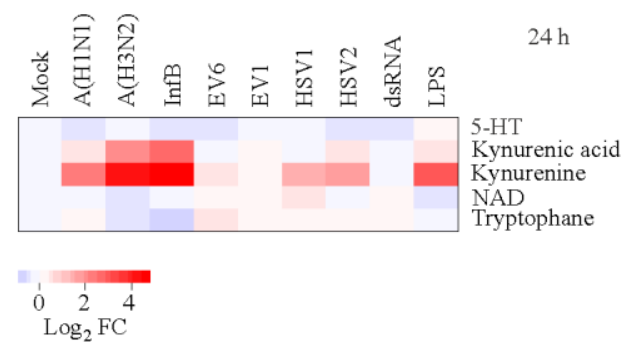

Fig. 3. KP is activated in human primary human macrophages in response to viral infections or dsRNA- or LPS- stimulation. A. Macrophages from healthy donors were infected with mock, A/WSN/1933(H1N1), A/Udorn/307/1972 (H3N2), B/Shandong/7/97, EV6, EV1, HSV1, HSV2 (moi 3 for all viruses) or treated with E.coli LPS $(1 \mu \mathrm{g} / \mathrm{ml})$ or bacteriophage phi6 dsRNA $(1 \mu \mathrm{g} / \mathrm{ml})$. After $24 \mathrm{~h}$ cell viability was measured by CTG and results were plotted. Mean \pm standard deviation (SD), $\mathrm{n}=3$. B. Cells were treated as for panel A. Eight hours post infection cells were collected, total RNA was isolated and subjected to genome-wide transcription profiling. A heatmap map of IFN and KP genes is shown. Rows represent gene symbols, columns represent treatments. Each cell is coloured according to the $\log 2$-transformed and quantile-normalized expression values of the samples, 
expressed as fold-change relative to the average of mock controls. C. Macrophages were treated as for panel A. Eight hours post infection cells were collected, total cellular RNA was isolated and the expression of cellular IDOI and IFNBI genes was analyzed using RT-qPCRs. The mock-control value is set to 1 . Mean $\pm S D, n=3$. Statistically significant ( $p<0.05$, T-test) differences in gene expression between mock and virus infected/stimulated cells are indicated with asterisks. D. Macrophages were mock- or A/Udorn/1972(H3N2)-infected (moi 3). The synthesis of cellular IDO1 was analyzed at different time points by Western blotting. GAPDH was used as a loading control and viral NS1 and NP were used to monitor virus replication. E. Macrophages were infected as for panel A. After $24 \mathrm{~h}$ the cell culture supernatants were collected, and metabolite levels were determined by LC-MS/MS. A heat map of selected metabolites is shown. Rows represent metabolites, columns represent treatments. Each cell is coloured according to the average of log2-transferred profiling values of triplicate samples, expressed as fold-change relative to the average of mock controls.

A

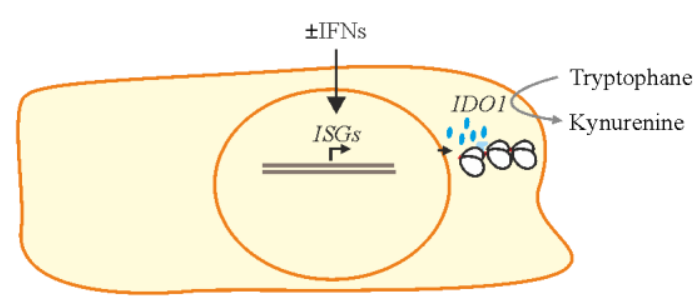

D

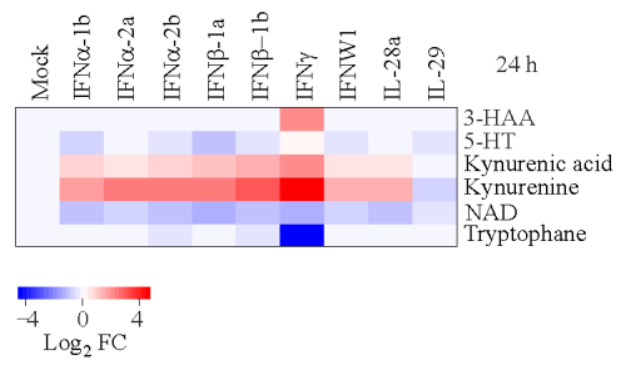

B

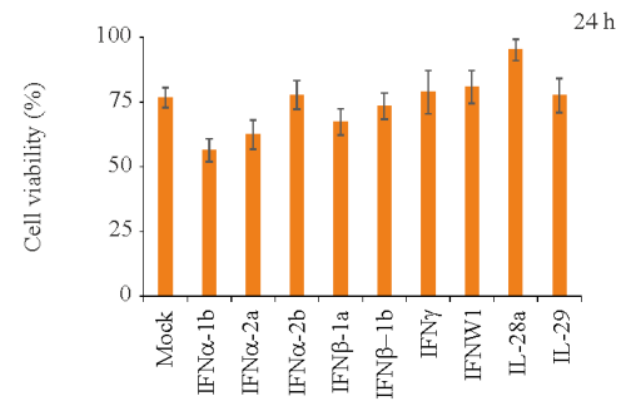

$\mathrm{C}$

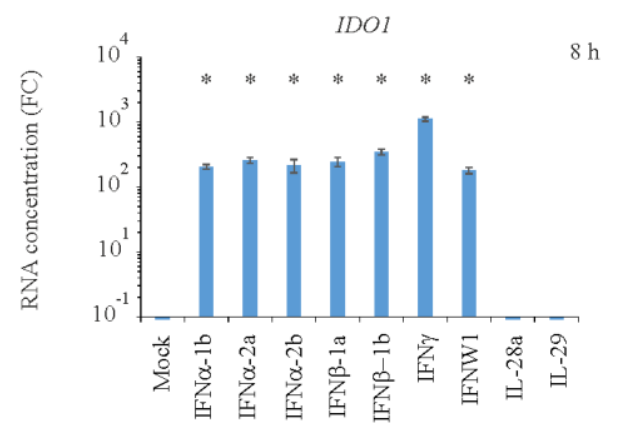

Fig. 4. IFNs regulate the IDO1-mediated KP in human macrophages. A. Schematic representation of the experimental setup. B. Macrophages were stimulated with purified recombinant human IFNs (1 $\mu \mathrm{g} / \mathrm{ml}$ ) or non-stimulated. After $24 \mathrm{~h}$ cell viability was measured by CTG and results were plotted. Mean \pm SD, $n=3$. C. Cells were treated as for panel B. Eight hours post infection cells were collected, total RNA was isolated and the expression cellular IDO1 gene was analysed using RT-qPCRs. Mean $\pm \mathrm{SD}, \mathrm{n}=3$. Statistically significant $(\mathrm{p}<0.05$, T-test) differences in gene expression between non- and IFN-stimulated cells are indicated with asterisks. D. Macrophages were stimulated as for panel B. After $24 \mathrm{~h}$ the cell culture supernatants were collected, and metabolite levels were determined by LCMS/MS. A heat map of selected metabolites is shown. Rows represent metabolites, columns represent treatments. Each cell is coloured according to the log2-transformed profiling values of samples, expressed as fold-change relative to the average of mock controls.

This article is protected by copyright. All rights reserved. 
A

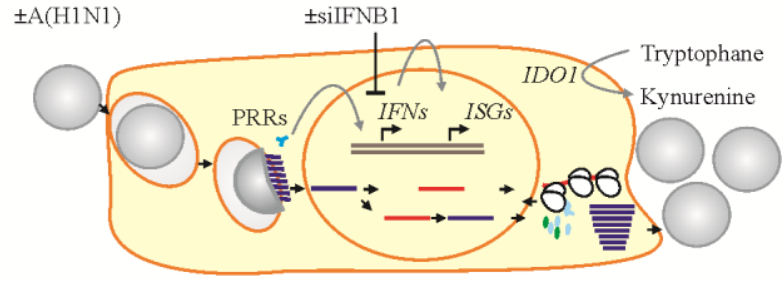

B

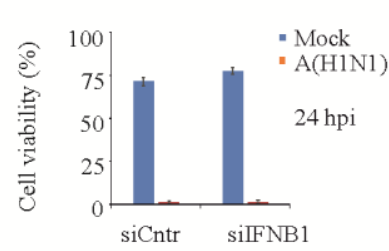

$\mathrm{C}$
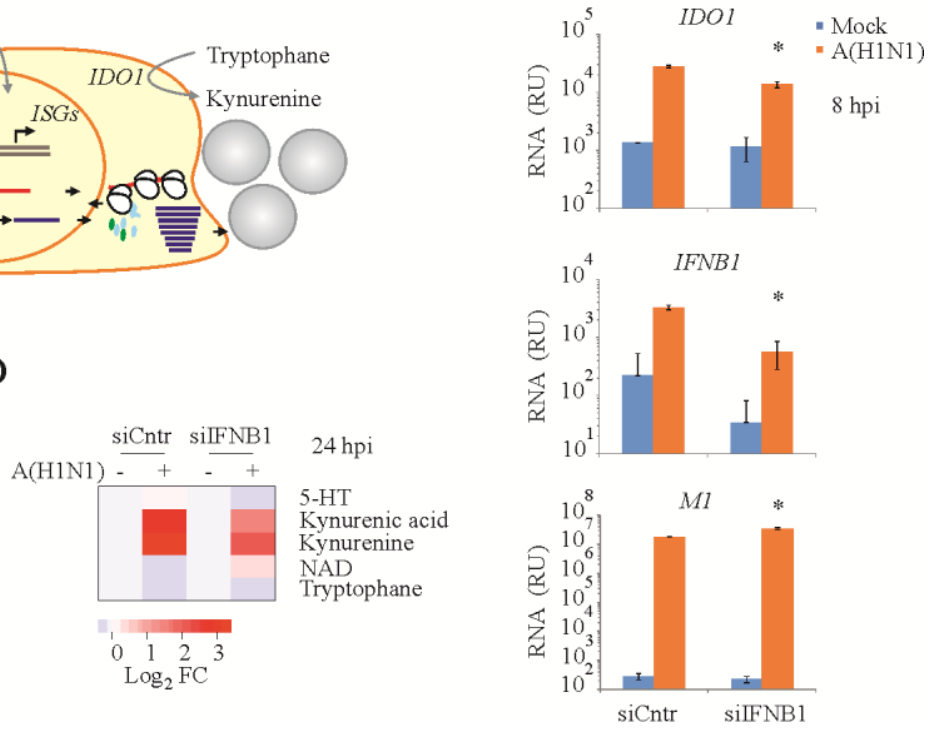

Fig. 5. IFN $\beta$ regulates the IDO1-mediated KP in human RPE cells. A. Schematic representation of the experimental setup. B. RPE cells were transfected with IFNB1-targeted or non-targeted control siRNAs. Twenty-four hours later cells were infected with WSN (moi 3) or mock. After $24 \mathrm{~h}$ cell viability was measured by $C T G$ and results were plotted. Mean $\pm S D, n=3$. C. Cells were treated as for panel B. Eight hours post infection cells were collected, total RNA was isolated and the expression cellular IDOI, IFNBI and viral $M I$ genes was analysed using RT-qPCRs. Mean $\pm \mathrm{SD}, \mathrm{n}=3$. Statistically significant ( $\mathrm{p}<0.05$, T-test) differences in gene expression between IFNBI-targeted and non-targeted IAV-infected cells are indicated with asterisks. D. Cells were treated as for panel B. After $24 \mathrm{~h}$ the cell culture supernatants were collected, and metabolite levels were determined by LCMS/MS. A heat map of selected metabolites is shown. Rows represent metabolites, and columns represent treatments. Each cell is coloured according to the log2-transformed profiling values of samples, expressed as fold-change relative to the average of non-targeted siRNAs treated mockinfected controls.

This article is protected by copyright. All rights reserved. 
A

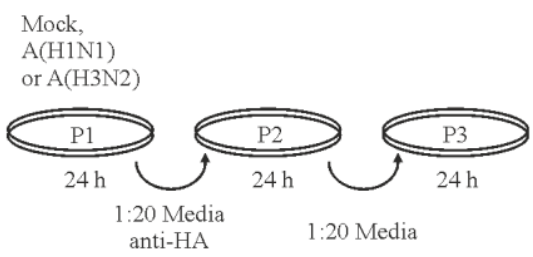

B

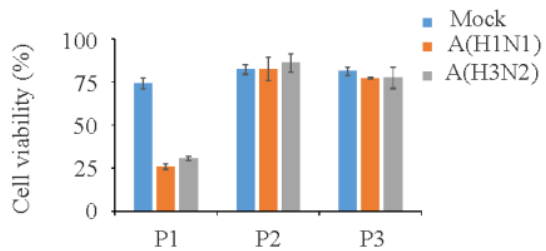

D

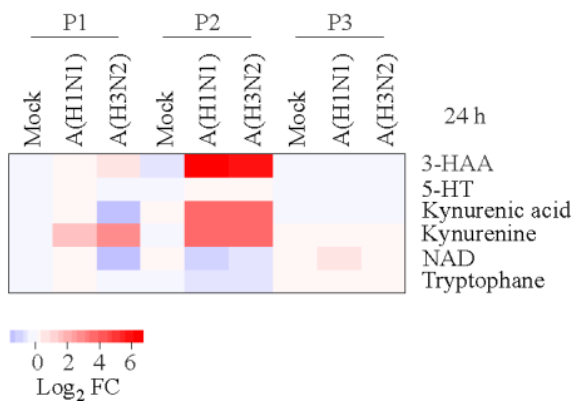

$\mathrm{C}$

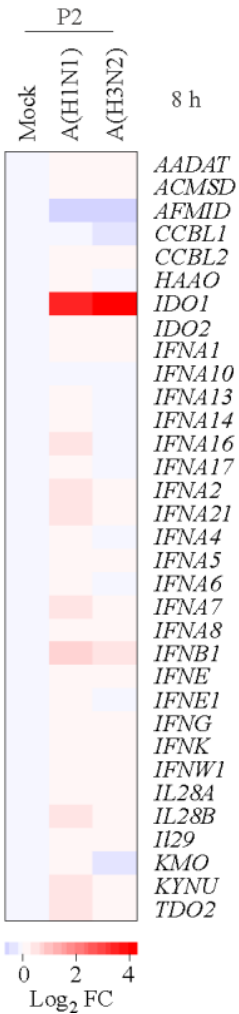

Fig. 6. IFNs produced by IAV-infected cells induces the IDO1-mediated KP in non-infected macrophages.

A. Schematic representation of the experimental setup. A. Macrophages (P1) were infected with IAV (moi 3) or mock. After 1 hour, the media were changed to a fresh one. After $24 \mathrm{~h}$ the media were collected, treated with anti-HA antibodies and diluted with fresh medium. The media was applied to macrophages (P2) from the same donor. After $24 \mathrm{~h}$ the media were collected from M2 cells, and diluted with fresh medium. The media was then applied to macrophages (P3) from the same donor. After 24 h cell viability was measured by $C T G$ and results were plotted. Mean $\pm S D, n=3$. C. Cells were treated as for panel B. RNA was extracted from P2 cells after $8 \mathrm{~h}$ post treatment and subjected to genome-wide transcription profiling. A heatmap map of IFN and KP genes is shown. Rows represent gene symbols, columns represent treatments. Each cell is coloured according to the log2-transformed and quantile-normalized expression values of the samples, expressed as fold-change relative to the average of mock controls. D. Cells were treated as for panel B. Media from P1, P2 and P3 cells were collected after $24 \mathrm{~h}$ post infection/treatment, and metabolite levels were determined by LC-MS/MS. A heat map of selected metabolites is shown. Rows represent metabolites, and columns represent treatments. Each cell is coloured according to the log2-transformed values of samples, expressed as fold-change relative to the average of M1 mock controls.

This article is protected by copyright. All rights reserved. 
A

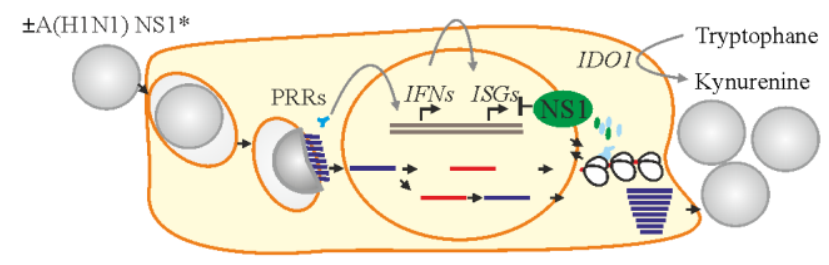

B

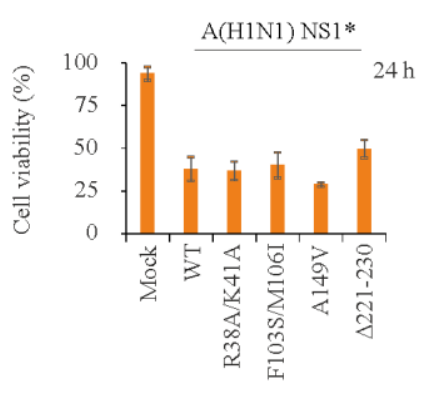

$\mathrm{C}$
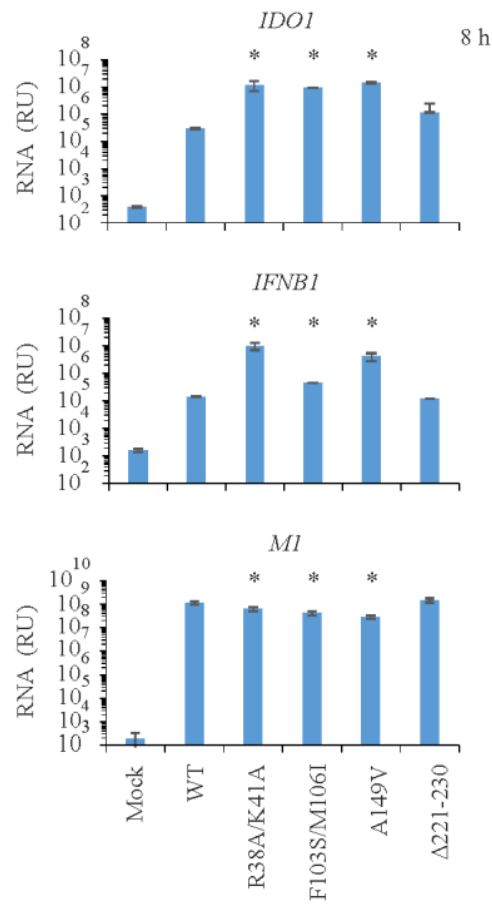

Fig. 7. IAV via its NS1 protein attenuates kynurenine biosynthesis. A. Schematic representation of the experimental setup. The picture also shows how newly synthetized influenza NS1 protein likely attenuates the transcription of IFNBI and IDOI genes. B. Macrophages were infected with mock, wild type WSN strain or its NS1 mutant variants (moi 3). After $24 \mathrm{~h}$ cell viability was measured by $\mathrm{CTG}$ and results were plotted. Mean $\pm \mathrm{SD}, \mathrm{n}=3$. C. Cells were treated as for panel B. RNA was extracted after $8 \mathrm{~h}$ post infection and the expression of cellular IDOI, IFNBI and viral $M 1$ genes was analysed using RT-qPCRs. Mean $\pm \mathrm{SD}, \mathrm{n}=3$. Statistically significant $(\mathrm{p}<0.05$, T-test) differences in gene expression between mutant- and wild type virus-infected cells are indicated with asterisks. $\mathbf{D}$. Cells were infected as for panel B. Media were collected after $24 \mathrm{~h}$ post infection, and metabolite levels were determined by LC-MS/MS. A heat map of selected metabolites is shown. Rows represent metabolites, columns represent treatments. Each cell is coloured according to the log2-transformed values of samples, expressed as fold-change relative to the average of mock controls.

This article is protected by copyright. All rights reserved. 
A

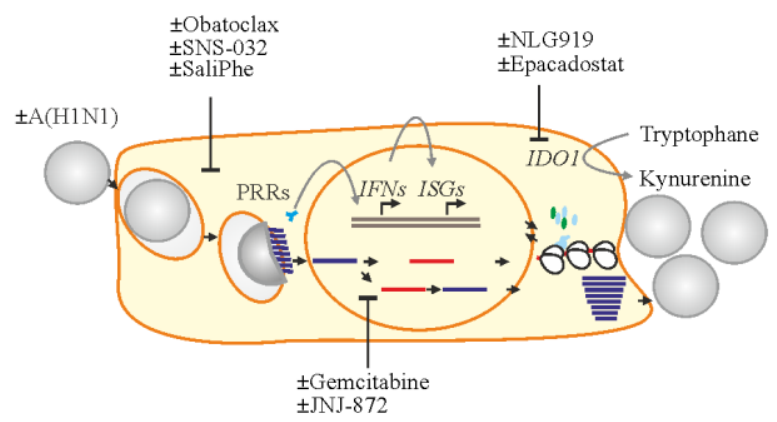

$\mathrm{D}$

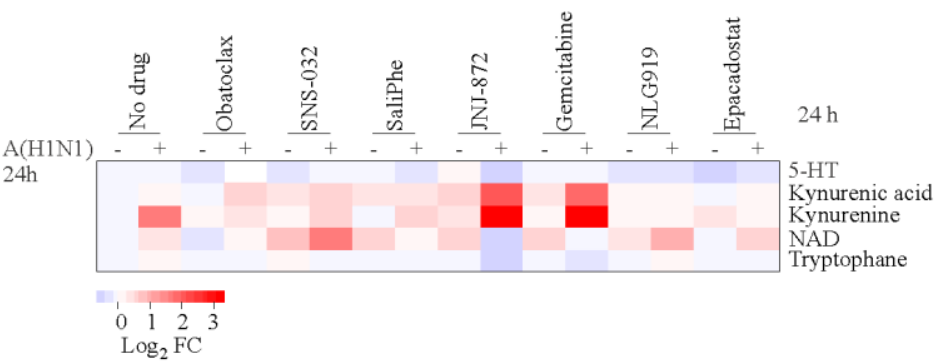

B

$\mathrm{C}$
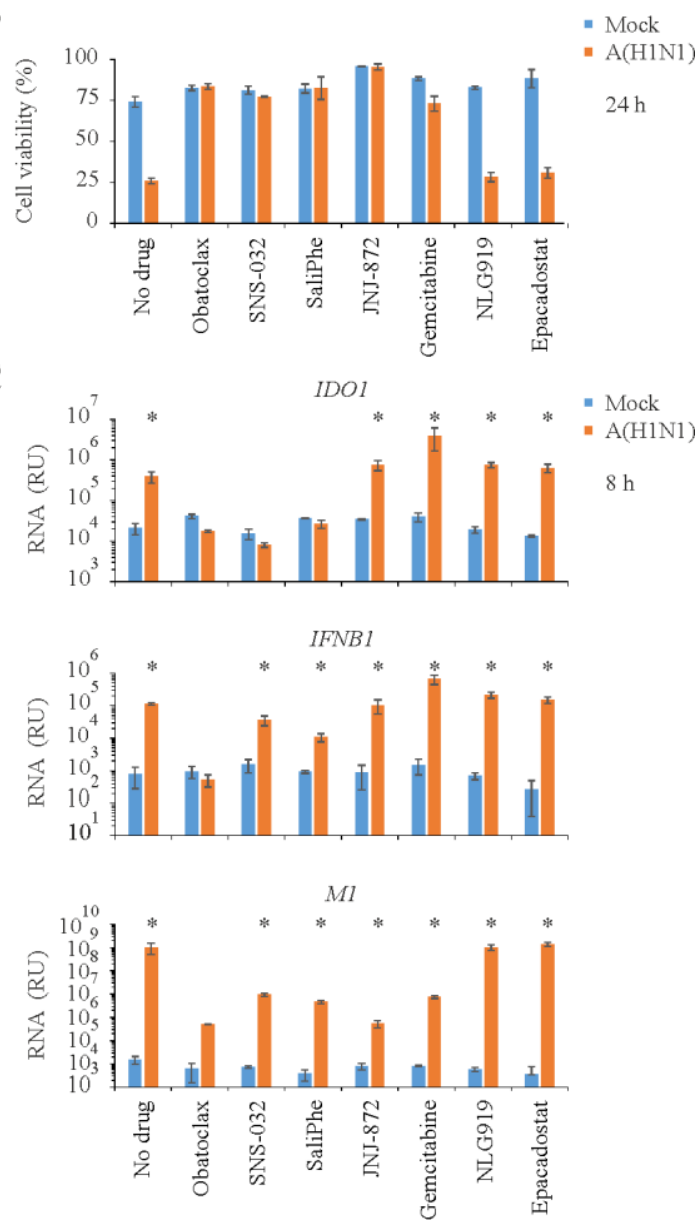

Fig. 8. Effect of antiviral compounds and IDO1 inhibitors on KP in IAV-infected human macrophages. A. Schematic representation showing the effect of antiviral compounds on virus entry and viral RNA transcription and replication. Two IDO inhibitors targeting IDO1 are also shown. B. Macrophages were treated with $2 \mu \mathrm{M}$ obatoclax, $0.1 \mu \mathrm{M}$ SNS-032, $3 \mu \mathrm{M}$ SaliPhe, $0.1 \mu \mathrm{M}$ JNJ872, 1 $\mu \mathrm{M}$ gemcitabine, $1 \mu \mathrm{M}$ epacadostat or $1 \mu \mathrm{M}$ NLG919 or remained non-treated and infected with mock or IAV (moi 3). After $24 \mathrm{~h}$ cell viability was measured by CTG and results were plotted. Mean \pm SD, $\mathrm{n}=3$. C. Cells were treated as for panel B. RNA was extracted after $8 \mathrm{~h}$ post infection and the expression of cellular IDOI, IFNBI and viral $M 1$ genes was analysed using RT-qPCRs. Mean $\pm \mathrm{SD}$, $\mathrm{n}=3$. Statistically significant ( $\mathrm{p}<0.05$, T-test) differences in gene expression between virus- and mockinfected cells are indicated with asterisks. D. Cells were treated as for panel B. Media were collected after $24 \mathrm{~h}$ post infection, and metabolite levels were determined by LC-MS/MS. A heat map of selected metabolites is shown. Rows represent metabolites, columns represent treatments. Each cell is coloured according to the $\log 2$-transformed values of samples, expressed as fold-change relative to the average of mock controls.

This article is protected by copyright. All rights reserved. 